\title{
RUPTURED MALIGNANT GERM CELL OVARIAN TUMOR IN A 14 YEAR OLD GIRL: A CASE REPORT
}

\author{
P. Sunita Sudhir ${ }^{1}$, Sunita Mishra², Vrunda Choudary³, Komal ${ }^{4}$
}

\section{HOW TO CITE THIS ARTICLE:}

P. Sunita Sudhir, Sunita Mishra, Vrunda Choudary, Komal. "Ruptured Malignant Germ Cell Ovarian Tumor in a 14 year Old Girl: A Case Report". Journal of Evolution of Medical and Dental Sciences 2014; Vol. 3, Issue 41, September 04; Page: 10423-10427, DOI: 10.14260/jemds/2014/3356

ABSTRACT: Immature teratoma accounts for $10-20 \%$ of all ovarian neoplasms in women less than 20 years of age with peak incidence between 15 - 19 years and they account for $30 \%$ of deaths arising from ovarian cancer in this age group.(1) Immature teratomas are rarely found to be bilateral,(2) Immature teratomas are malignant in nature and the most common sites of dessemination are peritoneum, retroperitoneal lymph nodes, hematogenous spread to Lung liver and brain is unusual.(3) We report a case of an immature teratoma of the ovary in a 14 year old girl who presented to us with acute pain abdomen. On examination patient was febrile, tachycardia present and abdominal rigidity was seen. Ultrasound examination showed a pelvic mass with fluid in morrisons pouch suggesting internal haemorrhage. Urine pregnancy test was done to rule out ectopic pregnancy. Patient was taken for emergency laparotomy. On laparotomy ruptured ovarian mass was seen with hemoperitoneum. Unilateral salpingo - oophorectomy was done and specimen sent for Histopathological examination which revealed immature ovarian teratoma stage I, Grade 3. Postoperative period was uneventful. Patient was referred to cancer centre for chemotherapy and further management. Patient was put on BEP regime.(Bleomycin Etoposide, Paclitaxal).on further follow up patient was normal.

KEYWORDS: Immature Teratoma, ovarian Malignancy, Germ cell tumor, Fertility, Chemotherapy.

INTRODUCTION: Immature ovarian teratomas are ovarian germ cell tumors arising from primordial germ cells in the gonads. They are less common as compared to mature ovarian teratomas. They constitute of less than $1 \%$ of all ovarian teratomas.(4) Most commonly seen in younger age group in first two decades of life accounting for 10 - $20 \%$ malignant ovarian tumours in this age group.

Immature ovarian teratomas can be differentiated from mature ovarian teratomas by their histological differentiation and malignant behavior of the tumor.

Most common mode of presentation is either abdominal (pelvic) mass or pain abdomen. in rare cases it may rupture or undergo torsion and present as acute abdomen as seen in present case.

An immature cystic teratoma is characterized by the presence of immature tissue and amount of immature neuroepithelium component present correlates with the tumour grade and prognosis of the tumor(5) As per Norris classification it is graded from grade 0 to Grade 3. Grade -0 representing well differentiated neuroepithelium and Grade 3 representing poorly differentiated neuroepithelial elements.

Alpha Feto Protein is the most common tumor marker elevated in these cases. Radiological diagnosis can be made by ultrasound examination, CT and MRI which shows variable degree of calcification, fat and cystic component. Treatment of immature ovarian teratoma is mainly surgical, for premenopausal patients, confined to a single ovary unilateral oophorectomy and surgical staging 
is done and depending upon the grade of the tumor chemotherapy and rarely radiotherapy is advised.

CASE REPORT: A 14 year old adolescent girl was received in causality with the complaint of severe pain abdomen since 5 - 6 hours. Pain was sudden in onset, continuous, all over the abdomen; there were no associated aggravating or relieving factors. She had regular menstrual cycles since menarche; last menstrual cycle was one week before the onset of pain.

On physical examination patient was in agony, pulse was $126 / \mathrm{min}$, regular, tachycardia was present, respiratory rate was 22 cycles per minute, temperature was $100^{\circ} \mathrm{F}$. Patient looked pale. respiratory system and CVS were normal. On abdominal examination there was guarding \& rigidity present.

Ultrasound examination showed solid mass of $11 \mathrm{~cm} \mathrm{X} 8 \mathrm{~cm}$ arising from the pelvis and there was free fluid with internal- echoes in the peri hepatic region, morrisons pouch and left and right iliac fossa.

Patient was taken up for emergency laparotomy with blood reserved. Operative findings included hemo peritoneum of $200-300 \mathrm{ml}$. Right sided twisted and ruptured ovarian mass of 10 X 8 $\mathrm{cm}$ with necrosis and hemorrhage was seen. Right fallopian tube was tortuous and oedematous. Left side ovary, fallopian tube, and ovaries were normal. Peritoneum appeared to be healthy Right sided salpingo-oopherectomy was done and specimen sent for Histopathological Examination (HPE). Postoperative period was uneventful and suture removal was done on $7^{\text {th }}$ day.

Blood investigation for serum tumor markers revealed:

- Alpha fetoprotein = 14.2 IU (0 -6 IU).

- Beta $\mathrm{HCG}=0.10 \mathrm{mIU} / \mathrm{ml}$.

- $\quad$ Ca $125=52.3 \mathrm{IU} / \mathrm{ml}(0.1-35 \mathrm{IU} / \mathrm{ml})$.

Histopathology examination showed immature teratoma with predominant neuroectodermal tissue - stage I, Grade 3.

Based on the above findings and HPE report diagnosis of immature teratoma of ovary stage I grade 3 was made. Considering the staging of tumor patient was referred to cancer centre for chemotherapy and further management. Patient was put on BEP regime.(Bleomycin Etoposide, Paclitaxal)

Patient was followed up for 2 months post chemotherapy and was found to be normal and symptom free. Post chemotherapy 2 months follow up scan showed normal left ovary.

DISCUSSION: Immature teratoma accounts for $10-20 \%$ of all ovarian neoplasias in women less than 20 years of age, with peak incidence between 15 and 19 years old, and 30\% of the deaths from ovarian cancer in this age group. Immature ovarian Teratoma rarely occurs during menopause.(1)

These tumors are histologically graded (grades 0 to 3 ) based on the amount and degree of neuroepithelial cell component immaturity. Older patients tend to have lower-grade tumors than younger patients. Immature teratomas are rarely found bilaterally. And benign tumor is found in contralateral ovary.(2) 
Immature Teratoma may present as a calcified pelvic mass, abnormal uterine bleeding, or pelvic pain. The most common sites of dissemination are the peritoneum and the retroperitoneal lymph nodes. Hematogenous spread to lungs, liver, or brain is unusual. They present with elevated levels of alpha-fetoprotein in $50 \%$ of cases.(3)

The youngest age reported in the literature is 5 years old. The initial presenting symptoms are usually abdominal distension or discomfort. The initial histopathology is usually immature teratoma.(6)

Imaging diagnosis of immature teratoma appears similar to mature teratoma due to its cystic appearance with fat content. CT with contrast and MRI will give better resolution in these cases.

In tumors of grade 2 or 3 , or with bilateral implants or recurrences, apart from surgery adjuvant chemotherapy should be indicated in a regimen of vincristine, actinomycin and cyclophosphamide (VAC), or Bleomycin, Etoposide and Cisplatin. ${ }^{(7,8)}$

In the present scenario young girl of 14 years presented with acute pain abdomen and based on ultrasound findings the patient was taken up for emergency laparotomy and diagnosis of immature teratoma confirmed by histopathological report and adjunctive chemotherapy was given as per grading of sage I grade 3. Timely diagnosis and management had good outcome.

CONCLUSION: It is important to diagnosis and manages cases of immature teratoma occurring in young girls who commonly present with acute abdomen. Proper management of these cases have good surgical outcome, depending upon the stage they can be taken up for adjunctive chemotherapy. Hence early diagnosis and management of these immature teratomas gives a favorable reproductive future in these young women.

\section{REFERENCES:}

1. Chabaud-Williamson M, Netchine I, Fasola S, Larroquet M, Lenoir M, Patte C, et al. Ovariansparing surgery for ovarian teratoma in children. Pediatr Blood Cancer. 2011; 57 (3): 429-34.

2. Outwater EK, Siegelman ES, Hunt JL. Ovarian teratomas: tumor types and imaging characteristics. Radiographics. 2001; 21 (2): 475-90

3. Saba L, Guerriero S, Sulcis R, Virgillio B, Melis G, Mallaraini G. Mature and immature ovarian teratomas: CT, US and MR imaging characteristics. Eur J Radiol. 2009; 72 (3): 454-63.

4. Outwater EK, Siegelman ES, Hunt JL. Ovarian teratomas: tumor types and imaging characteristics. Radiographics. 21 (2): 475-90.

5. Kumar V, Abbas AK, Fausto N. Robbins and Cotran pathologic basis of disease. W B Saunders Co. (2005) ISBN: 0721601871.

6. Lyliana Coutinho Resende Barbosa1, Antônio Marcos Coldibelli Francisco1, Silvânia de Cássia Vieira Archângelo1, Fabíola Campos Moreira Soares2, Maria Cláudia Tessari Ferreira2, Renata Leme Maia2: Bilateral immature ovarian teratoma in a 12-year-old girl: case report:Image In Medicine rev Assoc Med Bras 2012; 58 (2): 138-140

7. Kurata A, Hirano K, Nagane M, Fujioka Y. Immature teratoma of the ovary with distant metastases: favorable prognosis and insights into chemotherapeutic retroconversion. Int J Gynecol Pathol. 2010; 29 (5): 438-44. 


\section{CASE REPORT}

8. Mangili G, Scarfone G, Gadducci A, Sigismondi C, Ferrandina G, Scibilia G, et al. Is adjuvant chemotherapy indicated in stage I pure immature ovarian teratoma (IT)? A multicentre Italian trial in ovarian cancer (MITO-9). Gynecol Oncol. 2010; 119 (1): 48-52.

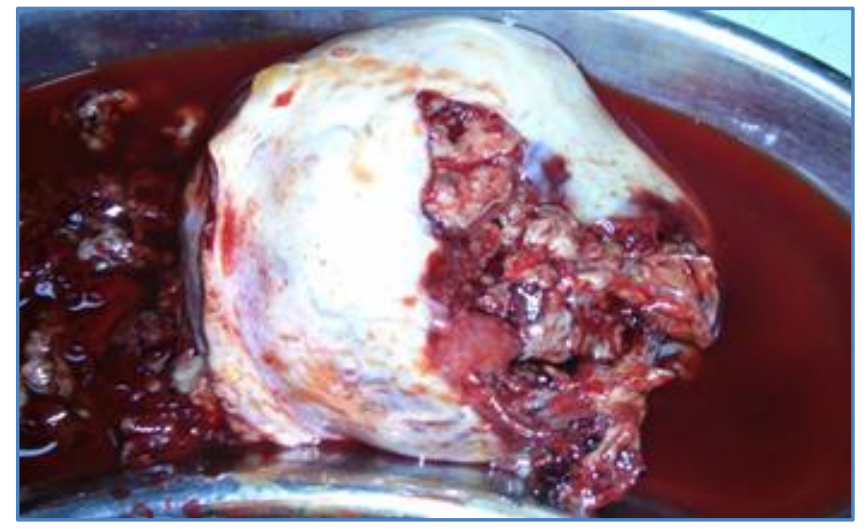

Fig. 1: Gross Specimen of Immature Teratoma showing necrosis and haemorrhages

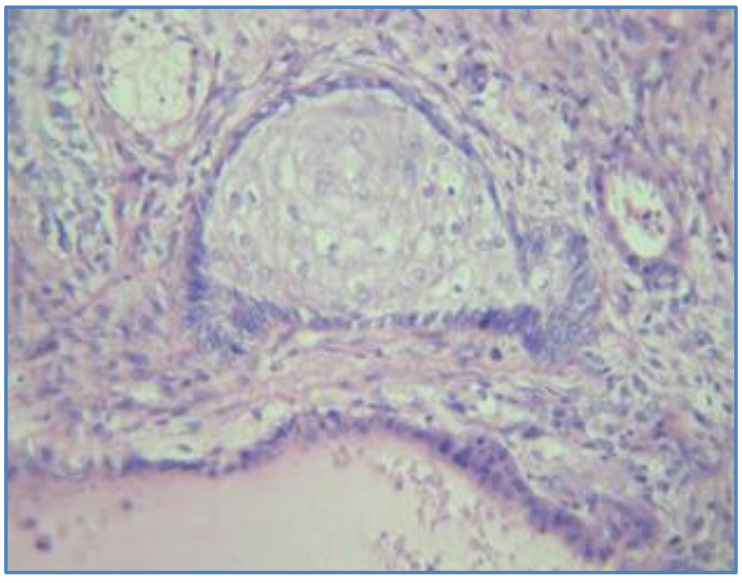

Fig. 2: HPE specimen showing primitive neuroepithelium

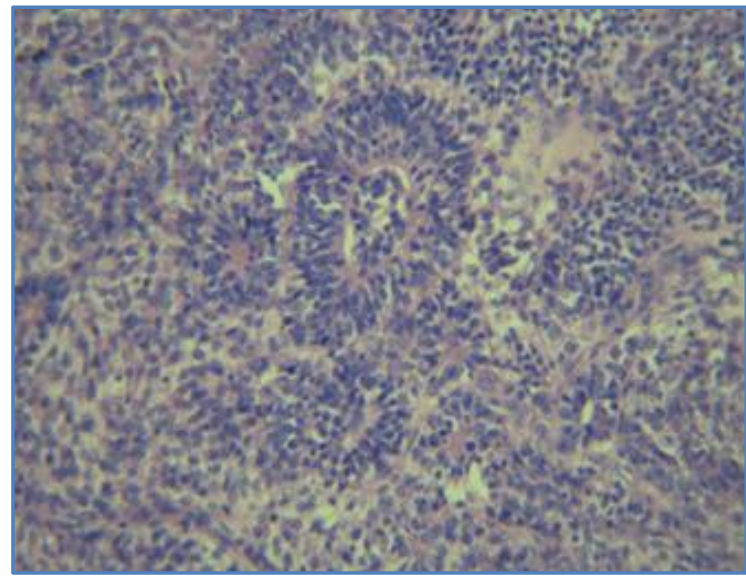

Fig. 3: HPE Specimen Showing Primitive Neural elements 


\section{CASE REPORT}

\section{AUTHORS:}

1. P. Sunita Sudhir

2. Sunita Mishra

3. Vrunda Choudary

4. Komal

\section{PARTICULARS OF CONTRIBUTORS:}

1. Assistant Professor, Department of Obstetrics and Gynaecology, Kamineni Institute of Medical Sciences, Narketpally.

2. Associate Professor, Department of Obstetrics and Gynaecology, Kamineni Institute of Medical Sciences, Narketpally.

3. Associate Professor, Department of Obstetrics and Gynaecology, Kamineni Institute of Medical Sciences, Narketpally.
4. Post Graduate, Department of Obstetrics and Gynaecology, Kamineni Institute of Medical Sciences, Narketpally.

\section{NAME ADDRESS EMAIL ID OF THE CORRESPONDING AUTHOR:}

Dr. P. Sunita Sudhir, Assistant Professor, Department of Obstetrics and Gynaecology, Kamineni Institute of Medical Sciences, Narketpally-508254, Nalagonda District, Telangana.

Email: spadgul@gmail.com

Date of Submission: 21/08/2014. Date of Peer Review: 22/08/2014. Date of Acceptance: 27/08/2014. Date of Publishing: 04/09/2014. 